\title{
Human dendritic cells sequentially matured with CD4+ T cells as a secondary signal favor CTL and long-term T memory cell responses
}

\author{
Thomas Simon*, Séverine Tanguy-Royer*, Pierre-Joseph Royer, Nicolas Boisgerault, Jihane Frikeche, Jean- \\ François Fonteneau and Marc Grégoire
}

Institut de Recherche Thérapeutique de I'université de Nantes, INSERMU892, Nantes, France.

\begin{abstract}
Dendritic cells (DCs) are professional antigen-presenting cells involved in the control and initiation of immune responses. In vivo, DCs exposed at the periphery to maturation stimuli migrate to lymph nodes, where they receive secondary signals from CD4+ T helper cells. These DCs become able to initiate CD8+ cytotoxic T lymphocyte (CTL) responses. However, in vitro investigations concerning human monocyte-derived DCs have never focused on their functional properties after such sequential maturation. Here, we studied human DC phenotypes and functions according to this sequential exposure to maturation stimuli. As first signals, we used TNF- $\alpha /$ polyI:C mimicking inflammatory and pathogen stimuli and, as second signals, we compared activated CD4+ T helper cells to a combination of CD40-L/ IFN- $\gamma$. Our results show that a sequential activation with activated CD4+ T cells dramatically increased the maturation of DCs in terms of their phenotype and cytokine secretion compared to DCs activated with maturation stimuli delivered simultaneously. Furthermore, this sequential maturation led to the induction of CTL with a long-term effector and central memory phenotypes. Thus, sequential delivery of maturation stimuli, which includes $\mathrm{CD} 4^{+} \mathrm{T}$ cells, should be considered in the future to improve the induction of long-term CTL memory in DC-based immunotherapy.
\end{abstract}

Key words: Cytotoxic T lymphocytes, dendritic cells, T memory cell, sequential maturation.

\section{INTRODUCTION}

The importance of DCs in adaptive immune responses has been extensively demonstrated in recent decades. DCs reside in skin, mucosa and peripheral tissues where they are exposed to foreign antigens. Through their capacity to sample their environment, to migrate to lymph nodes and to activate lymphocyte populations, these sentinel cells are at the origin of antigen-adapted immune responses, making a link between natural, innate and specific adaptive immunity (Banchereau and Steinman, 1998). In this context, DCs are at the heart of the immune surveillance mechanism, capturing and presenting antigens to specific $\mathrm{T}$ lymphocytes that can participate in response against pathogens or tumors.

Many studies in murine models have underlined the importance of CD4+ $\mathrm{T}$ cells in the induction of CD8+ T cell responses by DCs, and more recently in the establishment of a CD8+ T cell memory pool (Castellino and Germain, 2006). It is now well established in these animal models, that DCs must first be exposed to preliminary maturation signals in the periphery to induce their activation and migration to secondary lymphoid organs where they can interact and receive additional signals from $\mathrm{CD} 4+\mathrm{T}$ helper cells. CD4+ $\mathrm{T}$ cell help is mediated by several factors, such as CD40-L. CD40-L expressed by activated CD4+ $\mathrm{T}$ cells is known to induce an increase in the expression of co-stimulatory molecules by DCs and in the secretion of bioactive IL-12p70, a cytokine required for Th1 differentiation and CTL activation (Bennett, et al., 1997, Mackey, et al., 1998, Ridge, et al., 1998, Schoenberger, et al., 1998). However, CD40-L independent signals, such as IFN- $\gamma$, can also act on DCs to increase their capacities to initiate CTL responses (Lu, et al., 2000, Schroder, et al., 2004). In addition, it was recently demonstrated in a murine model that these CD4+ $\mathrm{T}$ cell-derived signals induce secretion of the chemokines CCL3 and CCL4 by DC. These chemokines are reported to attract naïve $\mathrm{CD} 8+\mathrm{T}$ cells, thus increasing the probability that an antigen-specific CD8+ precursor comes into contact with a mature antigenpresenting DC (Castellino and Germain, 2006, Castellino, et al., 2006, Arens and Schoenberger, 2010). Furthermore, these chemokines favored the differentiation of a long-term CD8+ T memory cell pool (Castellino and Germain, 2007, Obar and Lefrancois, 2010).

Thus, the murine models suggest that DC maturation require a two-step process in order to enable the efficient activation of CD8+ $\mathrm{T}$ cell responses and the generation of a $\mathrm{T}$ memory cell pool. Surprisingly, while numerous differences exist between murine and human DCs, no in vitro investigations concerning human DC maturation have taken into account this two-step maturation process. Indeed, they have focused on maturation stimuli, used alone or in combination, but delivered simultaneously, and not with $\mathrm{CD}^{+} \mathrm{T}$ lymphocytes as a second signal. Thus, in the present study, we characterized the phenotype and function of human DCs sequentially matured with activated CD4+ T cells as a second signal in comparison to DCs activated with simultaneous delivery of maturation stimuli. We set up a DC maturation protocol composed of TNF- $\alpha$ /polyI:C as a first combined signal that mimics the peripheral stimuli, followed by exposure to allogenic CD4+ T cells activated with CD3 and CD28 specific mAb. We investigated the effect of this sequential maturation on the phenotype of DC and their ability to secrete cytokines and chemokines. We also compared their capacity to prime antigen-specific $\mathrm{CD} 8+\mathrm{T}$ cell responses. We

*T. Simon and S. Tanguy-Royer contributed equally to this work.

Corresponding author: Dr. Marc Gregoire, INSERM U892, Institut de Recherche Thérapeutique de l'université de Nantes, 8 quai Moncousu BP70721, 44007 Nantes Cedex 1, France. Phone: +33-228-080-237; Fax: +33-240-084-082; E-mail: marc.gregoire@nantes.inserm.fr

Received: June 9, 2011. In revised form: November 4, 2011. Accepted: November 10, 2011. 
found that sequential maturation of human DCs, especially with activated CD4+ $\mathrm{T}$ cells as a second signal, lead to a better differentiation of anti-tumor CD8+ T cells with a longterm memory phenotype. Our work therefore reports a new approach using sequential maturation to optimize in vitro DC maturation and $\mathrm{T}$ cell activation for the development of DCbased immunotherapy.

\section{METHODS}

Cell culture

Human PBMCs were obtained at the Etablissement Français du Sang in Nantes from healthy donors (convention ATS 2000-12). After Ficoll-Paque density gradient centrifugation (Amersham, Uppsala, Sweden), monocytes were purified from PBMCs by elutriation using a Beckman Avanti J20 centrifuge equipped with a JE5.0 rotor and a $40 \mathrm{ml}$ elutriation chamber. Monocyte purity (>90\%) was assessed by flow cytometry using scatter gating to define monocyte and lymphocyte populations.

Monocytes were cultured in flasks at $2 \times 10^{6}$ cells $/ \mathrm{ml}$ in RPMI $1 \%$ penicillin-streptomycin-glutamin supplemented with 2\% human albumin (Laboratoire Français de Fractionnement et de Biotechnologies, Les Ulis, France), 500 $\mathrm{U} / \mathrm{ml}$ recombinant human GM-CSF and $40 \mathrm{ng} / \mathrm{ml}$ recombinant human IL-4 (both from CellGenix, Paris, France). Immature DCs were harvested at day 5 and cultured in fresh medium with cytokines at $1 \times 10^{6}$ cells $/ \mathrm{ml}$, in 24-well plates coated with poly(2-hydroxyethylmetacrylate) (Sigma, St Quentin Fallavier, France) to prevent cell adhesion. DC maturation was induced by the addition of TP: $20 \mathrm{ng} / \mathrm{ml}$ TNF- $\alpha$ (AbCys, Paris, France) and $50 \mu \mathrm{g} / \mathrm{ml}$ poly I:C (Sigma, St Quentin Fallavier, France), or CI: $0.5 \mu \mathrm{g} / \mathrm{ml}$ soluble CD40-L trimer (AbCys) and $1000 \mathrm{U} /$ ml IFN- $\gamma$ (AbCys), or T4+: activated CD4+ T cells at a DC/ $\mathrm{T} 4+$ ratio of $1 / 2$. In some conditions, $\mathrm{T} 4+$ or $\mathrm{CI}$ was added to DCs matured $10 \mathrm{hrs}$ with TP. In order to activate CD4+ T cells (T4+), allogeneic CD4+ T lymphocytes were incubated for 6 hours in 24-well plates, coated with $0.5 \mu \mathrm{g} / \mathrm{ml}$ of anti-CD3 $\mathrm{mAb}$ (Orthoclone OKT3, Janssen-Cilag, France) and $0.5 \mu \mathrm{g} /$ $\mathrm{ml}$ of anti-CD28 mAb (CD28.2, BD Biosciences, Paris, France), then washed and gamma-irradiated at 35 Gy to prevent proliferation.

The T2 cell line (Gift of T. Boon, Ludwig Institute for Cancer Research, Brussels) is a HLA-A*0201+ human T cell leukemia/B cell line hybrid defective for TAP1 and TAP2, thus expressing empty HLA class I molecules at its surface that can be loaded with exogenous peptides (Salter and Cresswell, 1986).

\section{Immunofluorescence and flow cytometry}

The surface phenotype of DCs was determined using the following PE-conjugated monoclonal antibodies (mAb): anti-CD80 (MAB104, Beckman-Coulter, Paris, France), antiCD86 (HA5.2B7, Beckman-Coulter), anti-CD83 (HB15a Beckman-Coulter), anti-CD40 (MAB89, Beckman-Coulter), anti-HLA-DR (Immu-357, Beckman-Coulter), and FITCconjugated anti-HLA-ABC mAb (B9.12.1, Beckman-Coulter). The fraction of responding CD8+ T cells was measured using APC-conjugated anti-CD8 mAb (RPA-T8, BD Biosciences) and PE-conjugated anti-IFN- $\gamma$ mAb (4S.B3, BD Biosciences). The memory phenotype of CD8+ T cells was determined using PECy5-conjugated anti-CD45RA mAb (HI100, BD Biosciences),
PE-conjugated anti-CCR7 mAb(150503, RD system), FITCconjugated anti-CD27 mAb (M-T271, BD Biosciences), APCconjugated anti-CD28 mAb (CD28.2, BD Biosciences), FITC- or PE-conjugated anti-CD45RO mAb (UCHL1, BD Biosciences) and FITC-conjugated anti-CD127 mAb (hIL-7R-M21, BD Biosciences).

For cell surface staining, cells were incubated with $\mathrm{mAb}$ diluted in PBS containing 10\% fetal calf serum (FCS, Sigma) for $30 \mathrm{~min}$ at $4^{\circ} \mathrm{C}$ in the dark, washed with PBS and then analyzed using a FACScalibur flow cytometer (Becton-Dickinson) and CellQuest Pro software. For IFN- $\gamma$ intracellular staining, cells were fixed in PBS containing 4\% paraformaldehyde (Electron Microscopy Science) for $10 \mathrm{~min}$ at room temperature, washed, permeabilized and stained with $\mathrm{mAb}$ in PBS containing $0.1 \%$ bovine serum albumin (BSA, Sigma) and 0.1\% saponin (Sigma) at room temperature. Cells were washed and analyzed by flow cytometry. The percentage of positive cells was determined by comparison to the staining observed with isotype controls (FITC- or PE-conjugated mouse immunoglobulin G1 (IgG1) and IgG2b, BD Biosciences).

Cytokine production measurement

DCs were plated at $1 \times 10^{6}$ cells/ml in RPMI $+2 \%$ human albumin, supplemented with maturation stimuli. Supernatants were harvested after $48 \mathrm{hrs}$ of maturation. Cytokine production was determined using a CBA kit (BD Biosciences) in accordance with the manufacturer's protocol. The kit enables the simultaneous measurement of IL-10, IL-12p70, IL-6, CCL3 (Mip1- $\alpha$ ) and CCL4 (Mip1- $\beta$ ) concentration by flow cytometry.

\section{$C D 8+$ stimulation by matured DCs}

CD8+ T lymphocytes were negatively selected using Rosette Sep, according to the manufacturer's instructions (Stem Cell). Cells were then washed and cultured in RPMI supplemented with $8 \%$ pooled human serum (pHS) prepared locally.

For the induction of Melan-A-specific CTL, HLA-A*0201+ CD8+ T lymphocytes were cultured with autologous matured DC loaded for $2 \mathrm{hrs}$ at $4^{\circ} \mathrm{C}$ with $10 \mu \mathrm{g} / \mathrm{ml}$ of Melan- $\mathrm{A}_{(26-35)}$ A27L peptide (ELAGIGILTV, Eurogenetec) in U-bottom 96well plates at a DC/T cell ratio of $1 / 10$. Some $20 \mathrm{U} / \mathrm{ml}$ of IL-2 (AbCys) and $5 \mathrm{ng} / \mathrm{ml}$ of IL-7 (AbCys) were added 5 and 7 days later, respectively. At day 6, the fraction of Melan-Aspecific CTL was measured by CD8/IFN- $\gamma$ co-staining after a $6 \mathrm{hrs}$ re-stimulation with $\mathrm{T} 2$ cells loaded with $10 \mu \mathrm{g} / \mathrm{ml}$ of Melan- $\mathrm{A}_{(26-35)} \mathrm{A} 27 \mathrm{~L}$ peptide in the presence of brefeldin A. The cytotoxic activity of Melan-A specific CTL was determined by ${ }^{51} \mathrm{Cr}$-release assay. At day 14 , the profile of the CD8+ T memory cells was determined by immunofluorescence and flow cytometry.

${ }^{51} \mathrm{Cr}$-release assay

Target cells (T2 cells) were pulsed for $1 \mathrm{hr}$ with $\mathrm{Na}_{2}{ }^{51} \mathrm{CrO}_{4}$ (NEN life science, Paris, France) and then washed. CD8+ T cells were co-cultured with $\mathrm{Na}_{2}{ }^{51} \mathrm{CrO}_{4}$-pulsed $\mathrm{T} 2$ cells loaded with Melan- $\mathrm{A}_{(26-35)}$ A27L peptides at several effector/target cell ratios. After $4 \mathrm{hrs}$ of culture at $37^{\circ} \mathrm{C}, 25 \mu \mathrm{L}$ of supernatant was harvested and added to a $100 \mu \mathrm{L}$ scintillation cocktail (optiphase supermix, Wallac, UK) before liquid scintillation counting. The percentage of specific lysis was calculated as 
follows: (sample release - spontaneous release/maximum release - spontaneous release) $x 100$. The spontaneous release was calculated from targets incubated with culture medium, and the maximum release from targets incubated with $1 \%$ Triton X-100 (Sigma).

Statistical analysis

Statistical significance was assessed using the Kruskal-Wallis nonparametric test and Dunn's multiple comparison post-hoc test with GraphPad Prism 4 software.

\section{RESULTS}

Optimal DC maturation is induced by sequential exposure to maturation signals

In a first set of experiments, we measured the expression of DC maturation markers induced by the delivery of activated CD4+ $\mathrm{T}$ cells (T4+) after an initial exposure to TNF- $\alpha$ and poly I:C (TP) and determined the optimal sequence of the addition of these signals (Fig. 1). Immature DCs (iDC) exposed for $48 \mathrm{hrs}$ to $\mathrm{TP}$, to allogeneic $\mathrm{T} 4+$ or to both maturation stimuli delivered simultaneously, acquired a mature phenotype with an increased expression of surface CD80, CD86, CD83 and HLA class I molecules (Fig. 1A). Interestingly, the maturation level of these DCs was strongly improved when T4+ were added $10 \mathrm{hrs}$ after the initial exposure to TP. The DC maturation level then decreased when the delay between exposure to TP and T4+ was extended to $24 \mathrm{hrs}$ and $48 \mathrm{hrs}$. These results suggest that matured DCs are more sensitive to T4+-derived signals $10 \mathrm{hrs}$ following initial exposure to TP and that this sensitivity then decreased because of their exhausted nature (Langenkamp, et al., 2000).

In addition to surface markers, we also measured cytokine productions by DC in culture supernatants (Fig. 1B). High levels of IL-6, IL-10 and IL-12 were observed in the culture of DC matured by the simultaneous addition of TP and T4+ (TP/T4+ sim). In comparison, high levels of IL-6 and IL-12 production were also measured for DCs matured sequentially by TP and, 10hrs later, activated CD4+ T cells, but the IL-10 production dropped dramatically. The addition of activated CD4+ T cells $24 \mathrm{hrs}$ or $48 \mathrm{hrs}$ after TP did not result in higher production of the three cytokines, confirming the observation shown in Figure 1A that DCs are less sensitive to CD4+ T cell signals $24 \mathrm{hrs}$ after the exposition to TP. Therefore, for all subsequent experiments, exposure to second signals was performed ten hours after exposure to TP and is referred as $\mathrm{TP}+\mathrm{T} 4+$.

Activated CD4+ $T$ cells as second signals dramatically increases $D C$ maturation

In a previous study, we reported that a combination of Poly $\mathrm{I}: \mathrm{C}$ and TNF- $\alpha$ induces DC maturation and that IL-12p70 production by mature DC can be increased by addition, several hours later, of activated CD4+ $\mathrm{T}$ cell signals such as IFN- $\gamma$ and CD40-L (Spisek, et al., 2003). In the present study, we used as first signals, TNF- $\alpha$ /polyI:C (TP) mimicking inflammatory and pathogen stimuli, and as second signals, we compared a combination of CD40-L/IFN- $\gamma(\mathrm{TP}+\mathrm{CI})$ to activated $\mathrm{CD} 4+\mathrm{T}$ cells $(\mathrm{TP}+\mathrm{T} 4+)$. We then analyzed the expression of a large panel of surface maturation markers: CD80, CD86, CD83, CD40, HLA class I and class II (Fig. 2). The strongest expression of these phenotypic markers was observed on DCs exposed first to TP and then, ten hours later, to T4+ as a second signal, with significant differences for CD86, CD83, CD40 and HLA ABC $(\mathrm{P}<0.05)$. However, the expression of the HLA-DR molecule was not amplified by the sequential delivery of T4+. Comparatively, when we tried to mimic the effects of the activated CD4+ T cells by providing DCs with a combination of soluble CD40-L plus IFN- $\gamma$ as a second signal $(\mathrm{TP}+\mathrm{CI})$, we also observed an increased maturation level, but not to the same extent as that observed when DCs were exposed to TP plus $\mathrm{T} 4+$. Our results suggest that the signal provided by activated CD4+ T cells to DCs cannot be mimicked by the simple addition of CD40-L and IFN- $\gamma$ and that additional stimuli are required.

To further define the effects of sequential exposure to TP and $\mathrm{T} 4+$ on DC maturation level, we measured the secretion of major cytokines (IL-6, IL-10 and IL-12p70) and chemokines

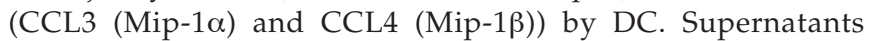
of the different DC cultures were analyzed by cytometric bead array (Fig. 3). We observed that secretion of IL-6, IL-10 and IL-12p70 by DC was induced by the mixture of TNF- $\alpha$ and Poly I:C as we previously reported (Spisek, et al., 2003). These secretions were significantly increased $(\mathrm{P}<0.05)$ by the sequential addition of activated CD4+ T cells, which, alone, did not produce any of these cytokines (data not shown).

In comparison, the addition of soluble CD40-L and IFN- $\gamma$ $(\mathrm{TP}+\mathrm{CI})$ after the first signal did not affect the production of IL-6, IL-10 and IL-12p70. Our results suggest that additional unknown signals delivered by activated CD4+ T cells participate with IFN- $\gamma$ and CD40-L to increase IL-12p70 secretion. In addition, we observed that secretion of CCL3 and CCL4 chemokines, which are implicated in the attraction of naïve T cells (Castellino, Huang, Altan-Bonnet, Stoll, Scheinecker and Germain, 2006), is also greatly increased by the sequential addition of $\mathrm{T} 4+$ ten hours after the exposure of DC to TP. Thus, the sequential combination of TNF- $\alpha$ / Poly I:C and activated CD4+ T cells conditions the DC to produce the maximum levels of the cytokines IL- 6 and IL-12p70 and the chemokines CCL3 and CCL4, associated with a highly mature surface phenotype. The large amount of IL-12p70 induced by the sequential maturation of DC by TP plus T4+ would probably provide a microenvironment favorable to the initiation and development of Th1 and CTL responses. In contrast, the amount of IL-10 production by TP plus T4+matured DCs has a negative effect on these $\mathrm{T}$ cell responses (O'Garra and Vieira, 2007).

$D C$ s matured sequentially with $C D 4+T$ cells as a second signal induce cytotoxic $C D 8+T$ cell responses against the tumor-associated antigen Melan- $A$

Since we observed a strong maturation profile and a high production of IL-12p70 by DCs sequentially matured by TP and T4+ (Fig. 2 and 3), we hypothesized that this sequential maturation would favor induction of CTL specific for a tumor-associated antigen. Thus, autologous HLA-A*0201+ CD8+ T lymphocytes from healthy donors were stimulated once with iDC or differentially matured DCs pulsed with the Melan- $\mathrm{A}_{26-35} \mathrm{~A} 27 \mathrm{~L}$ peptides derived from the melanocytic differentiation antigen Melan-A/MART1 (Fig. 4). After six 
A

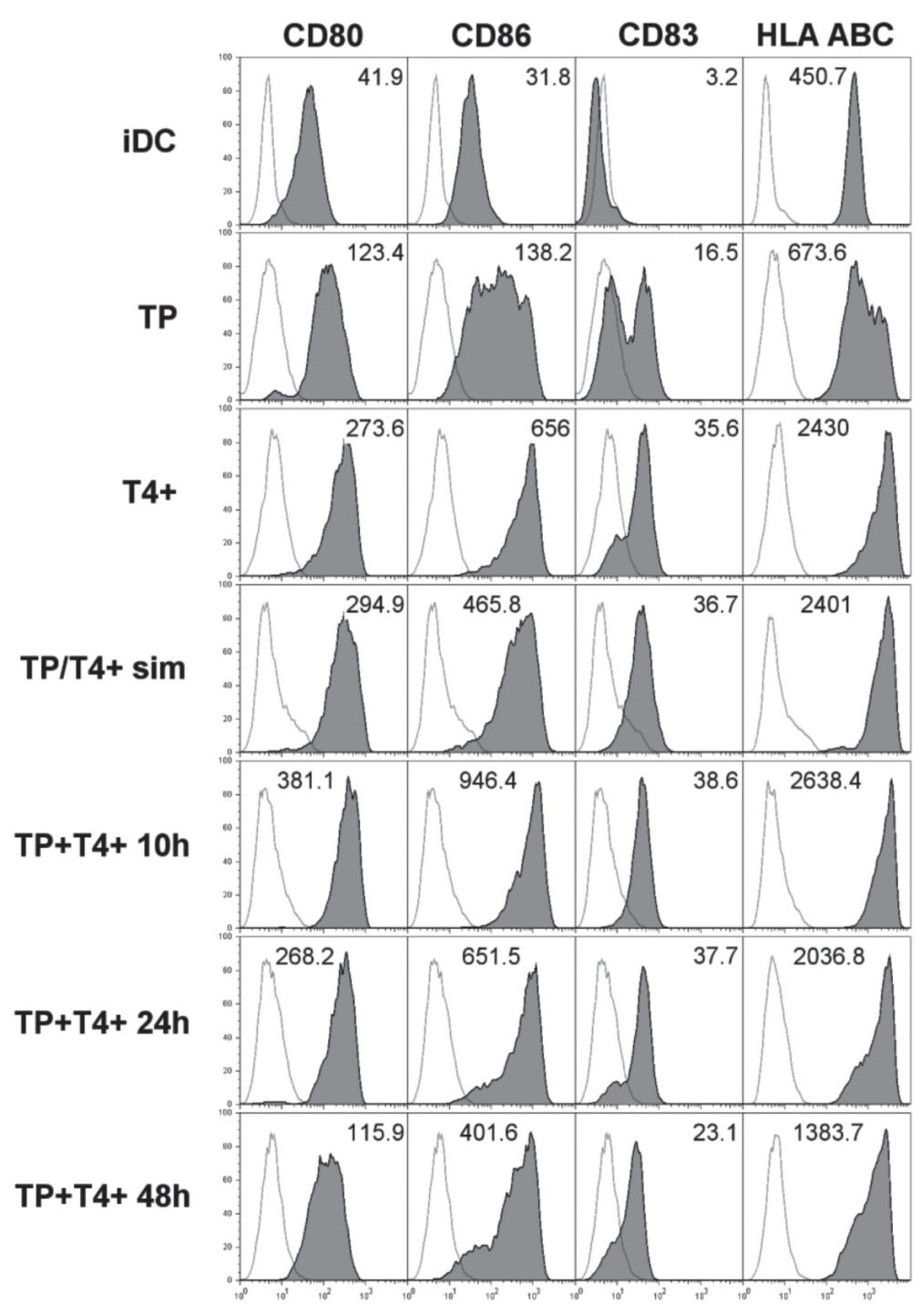

B
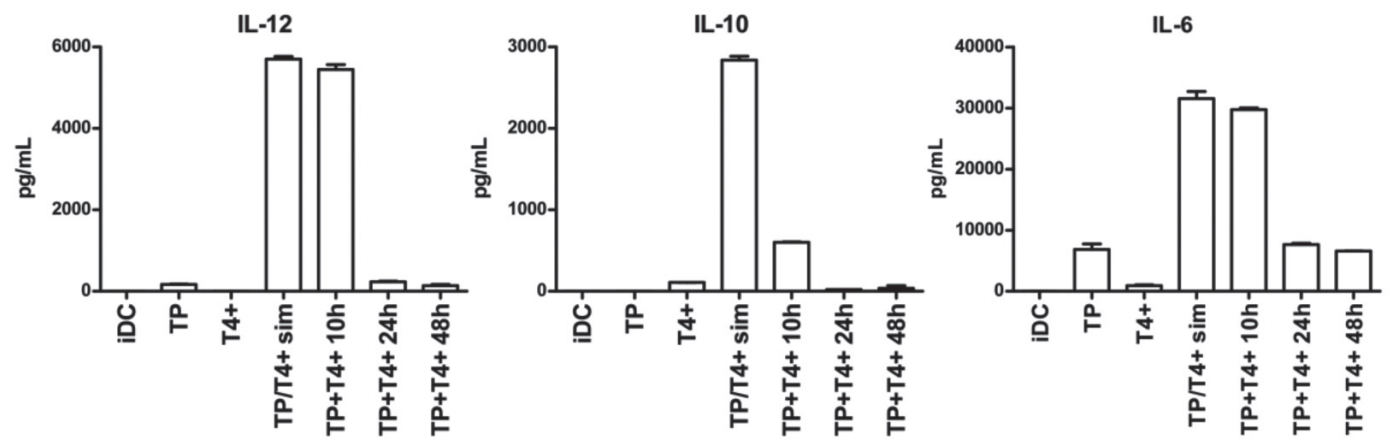

Fig. 1 Optimal DC maturation is induced by addition of activated CD4+ T cells as a second signal, ten hours after the first maturation signal. (A) phenotypic analysis of immature dendritic cells (iDC) and mature DC exposed for 48 hrs to different maturation stimuli: TNF- $\alpha$ and poly I:C (TP), irradiated activated CD4+ T cells (T4+), both stimuli added simultaneously (TP/T4+ sim) or TP followed by T4+, 10 hrs, $24 \mathrm{hrs}$ or $48 \mathrm{hrs}$ later $(\mathrm{TP}+\mathrm{T} 4+10 \mathrm{~h}, \mathrm{TP}+\mathrm{T} 4+24 \mathrm{~h}$ or $\mathrm{TP}+\mathrm{T} 4+48 \mathrm{~h}$ ). Median fluorescence intensity (MFI) is indicated on the corresponding histogram plot. (B) Analysis of IL-6, IL-10 and IL-12 production in the supernatant of DC culture exposed 48hrs to the different maturation stimuli. Measurement of cytokine production was performed by commercially available BD Cytometric Bead Array kits, according to the manufacturer's protocol. 
A

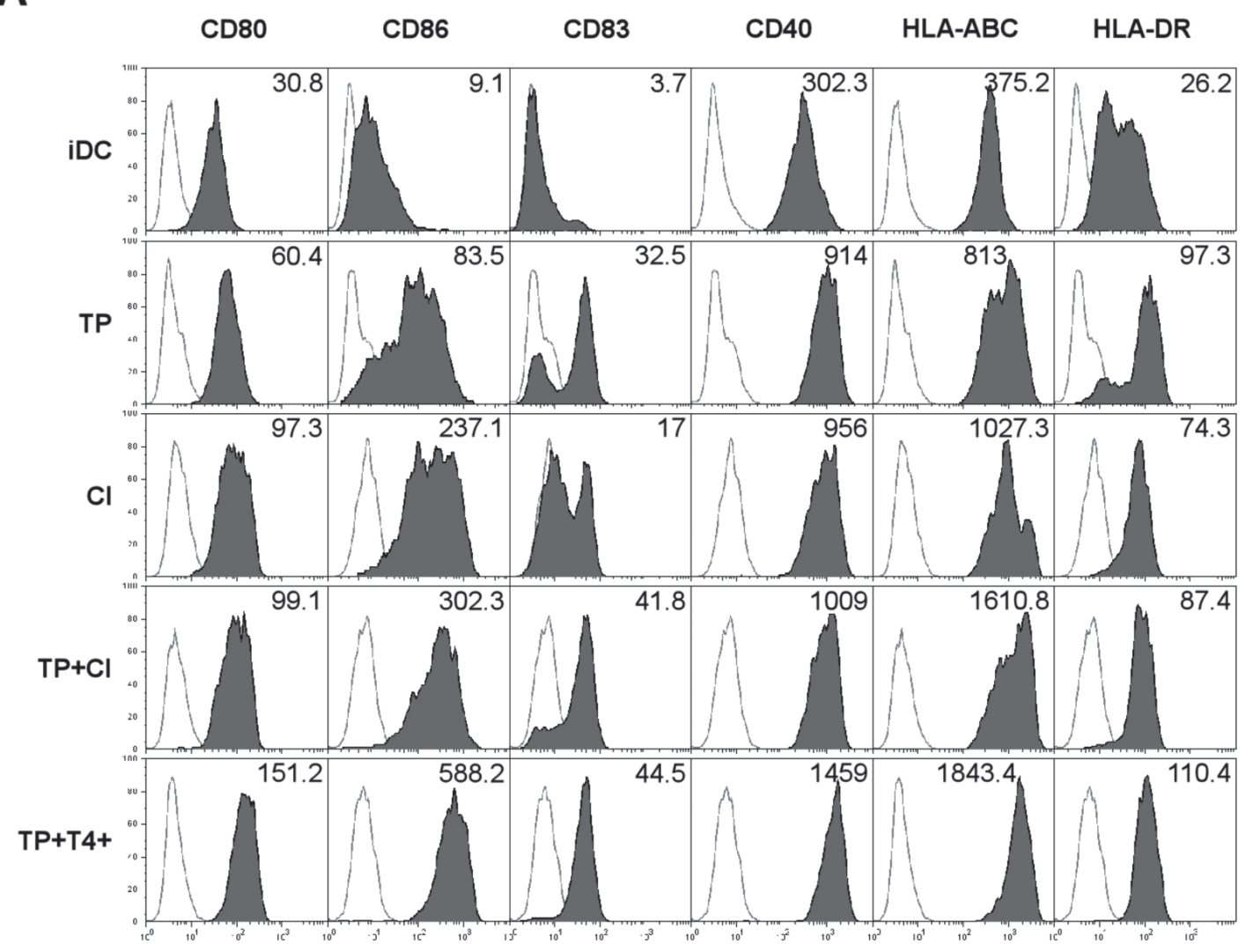

B
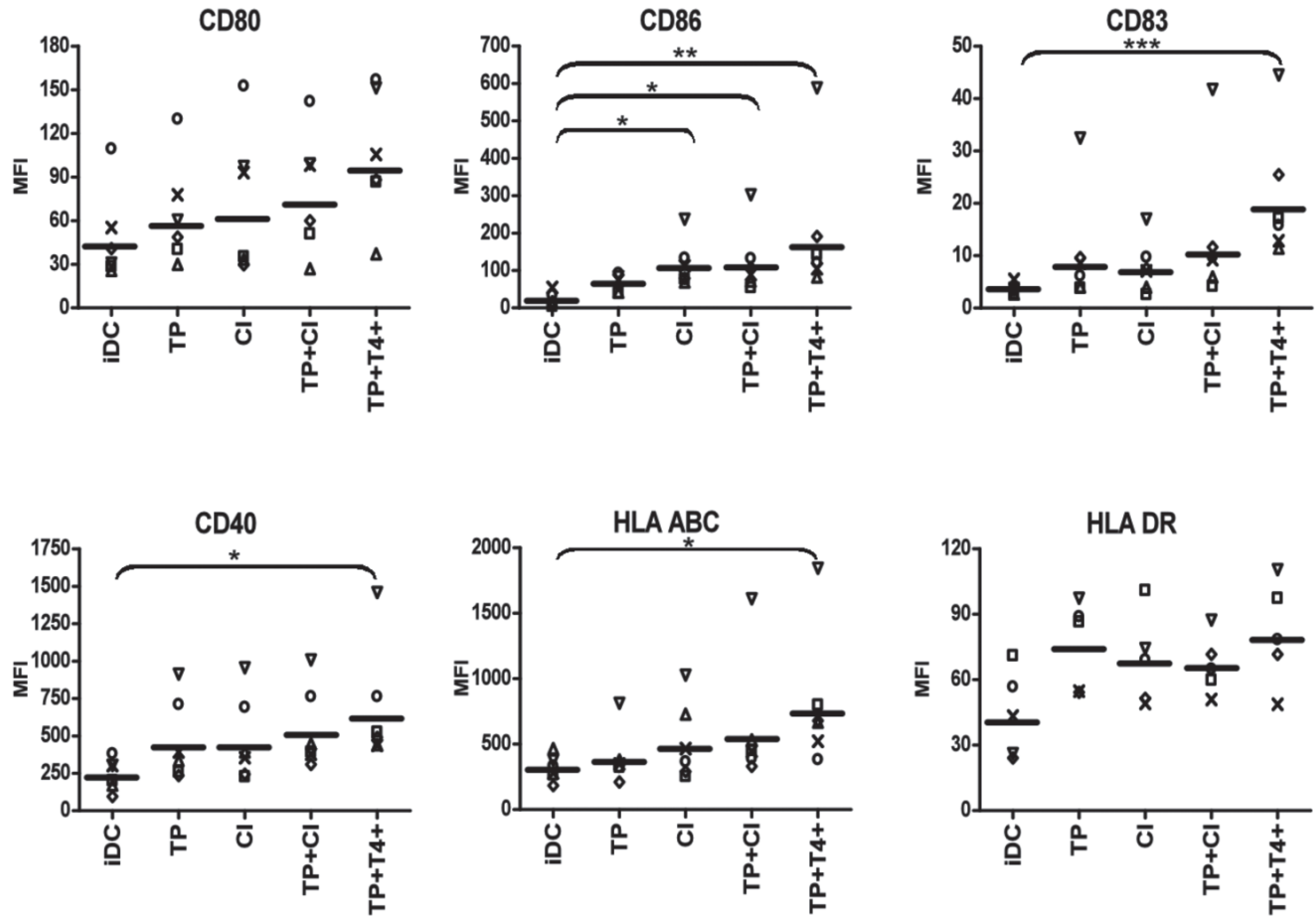

Fig. 2 DCs treated with activated CD4+ T cells as a secondary maturation signal exhibit a more mature phenotype. (A) Comparative phenotypic analysis of iDCs and mature DCs exposed for 48 hrs to different maturation stimuli: TNF- $\alpha$ and poly I:C (TP), CD40-L and IFN- $\gamma$ $(\mathrm{Cl})$, TP followed $10 \mathrm{hrs}$ later by $\mathrm{Cl}(\mathrm{TP}+\mathrm{Cl})$ and TP followed $10 \mathrm{hrs}$ later by $\mathrm{T} 4+(\mathrm{TP}+\mathrm{T} 4+)$. (B) Analysis from six healthy donors of iDC and mature DC phenotypes, exposed for 48 hrs to different maturation stimuli. Results are expressed as MFI and each symbol represents one donor. 
days of culture, part of the $\mathrm{T}$ cell population was stimulated by peptide-pulsed T2 cells in the presence of brefeldin A. The proportion of Melan-A-specific CTL was assessed by measurement of intracellular IFN- $\gamma$ and surface CD8 staining by flow cytometry (Fig. 4A and 4B). The greatest expansion of Melan-A-specific CTL was observed in the culture where CD8+ $\mathrm{T}$ cells were stimulated by DCs that had been sequentially matured by $\mathrm{TP}$ and $\mathrm{T} 4+$. Indeed, we observed two-fold more CD8+ T cells able to produce IFN- $\gamma$ in response to the Melan-A peptides in culture stimulated with peptide-pulsed DC sequentially matured by TP and T4+ compared to TPmatured DC. This difference was significant $(\mathrm{P}<0.01)$. The addition of CD40-L and IFN- $\gamma$ to DC matured with TP did not allow reaching the amplification level of Melan-A-specific CTL obtained with DCs matured with TP plus T4+. These results suggest that signals other than CD40-L and IFN- $\gamma$ are probably involved in the induction of Melan-A-specific CTL response.

The cytotoxic activity of the expanded Melan-A-specific CTL was also analyzed six days after the stimulation with DC, using Melan-A-pulsed T2 cells (Fig. 4C). Cytotoxic activities were well correlated to the Melan-A-specific CTL frequency determined by IFN- $\gamma /$ CD8 staining. The highest Melan-A/ MART-1 specific lysis was observed in the culture where CD8+ $\mathrm{T}$ cells were stimulated by DC matured with TP plus T4+, suggesting that sequentially matured DC prime functional cytotoxic T lymphocytes.
Anti-tumor cytotoxic CD8+ $T$ cells primed by sequentially matured $D C$ s with CD4 $+T$ cells as a second signal exhibit a long-term memory phenotype

It has been established in mouse models that CD4+ plays a role in the differentiation of long-term CD8+ T cell memory responses (Castellino and Germain, 2006). Thus, fourteen days after the stimulation we characterized the effector/memory phenotype of $\mathrm{T}$ cells surviving after the contraction phase in Melan-A-specific CTL cultures with markers currently used in the literature: CD27, CD28, CD45RO, CD45RA, CD127 and CCR7 (Powell, et al., 2005, Miller, et al., 2008). Cells were stained with an anti-CD45RO+ mAb to identify CD8+ $\mathrm{T}$ memory cells, and their expression of CD27, CD28 and CD45RA was analyzed (Fig. 5). Indeed, these three markers are expressed in naïve T cells, but tend to disappear upon the acquisition of effector function and are strongly re-expressed (CD27 and CD28) or moderately (CD45RA) when T cells acquire the memory phenotype. We found that a population of intermediate CD45RO+ CD27+ CD28+ CD45RA cells among the CD8+ T cells, persisted in the culture and were more frequent in the condition where DCs had received secondary signals from activated helper cells (TP+T4+). The combination of CD40-L, plus IFN- $\gamma$ as a second signal $(\mathrm{TP}+\mathrm{CI})$, had a weaker effect. We then studied CD127 (IL-7R $\alpha$ ) expression on this population. Indeed, it is now acknowledged that selective
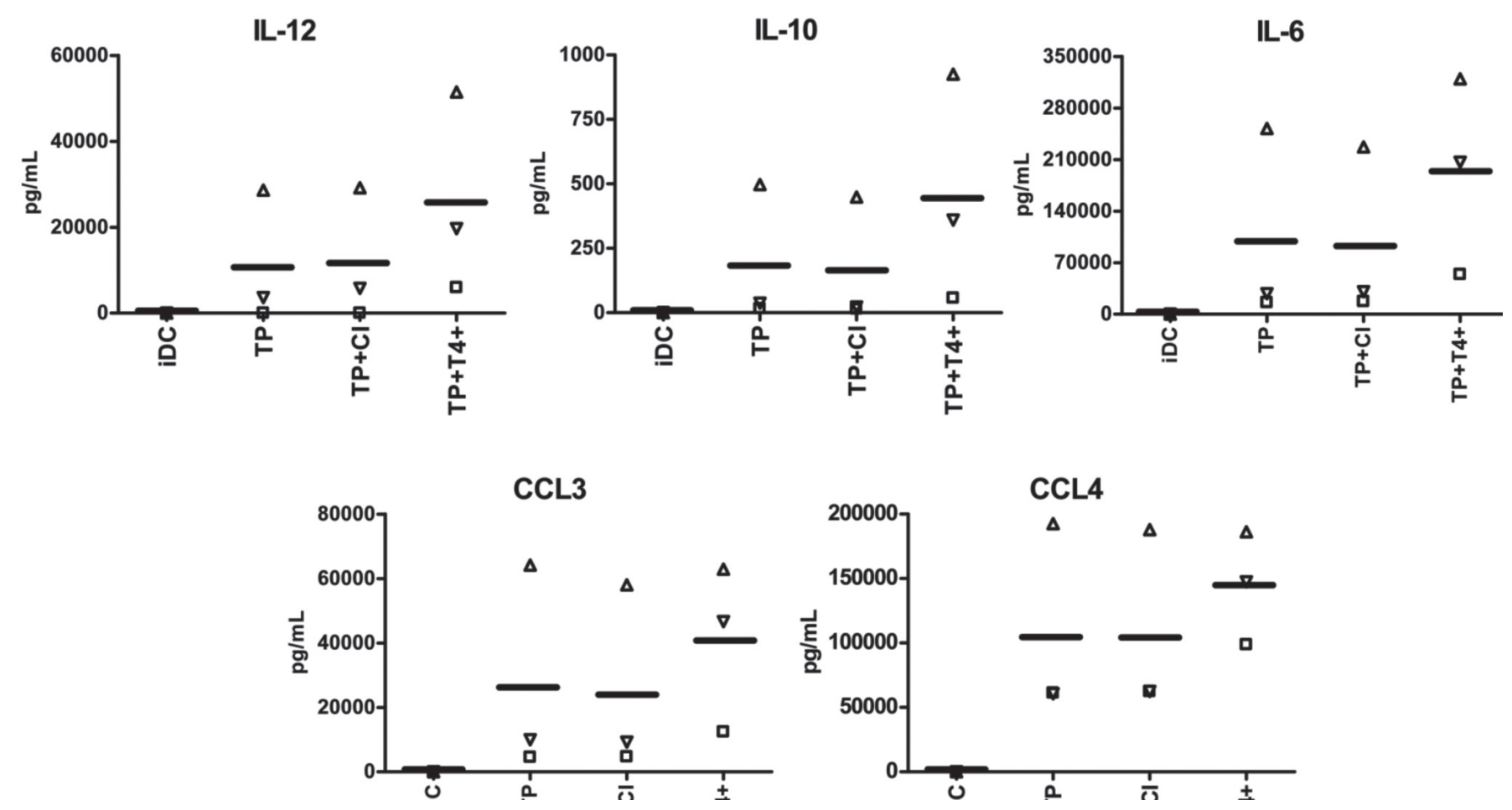

Fig. 3 DCs matured sequentially with CD4+ T cells as a secondary signal produce high levels of inflammatory cytokines and chemokines. Supernatants were collected from iDC and mature DCs exposed for 48 hrs to different maturation stimuli: TNF- $\alpha$ and poly I:C (TP), TP followed 10 hrs later by CD40-L and IFN- $\gamma(\mathrm{TP}+\mathrm{Cl})$ or T4+ (TP+T4+). Cytokines (IL-10, IL-12p70, IL-6) and chemokines (CCL3, CCL4,) were measured in supernatants using commercially available BD Cytometric Bead Array kits, according to the manufacturer's protocol. Each symbol represents one donor. 
A

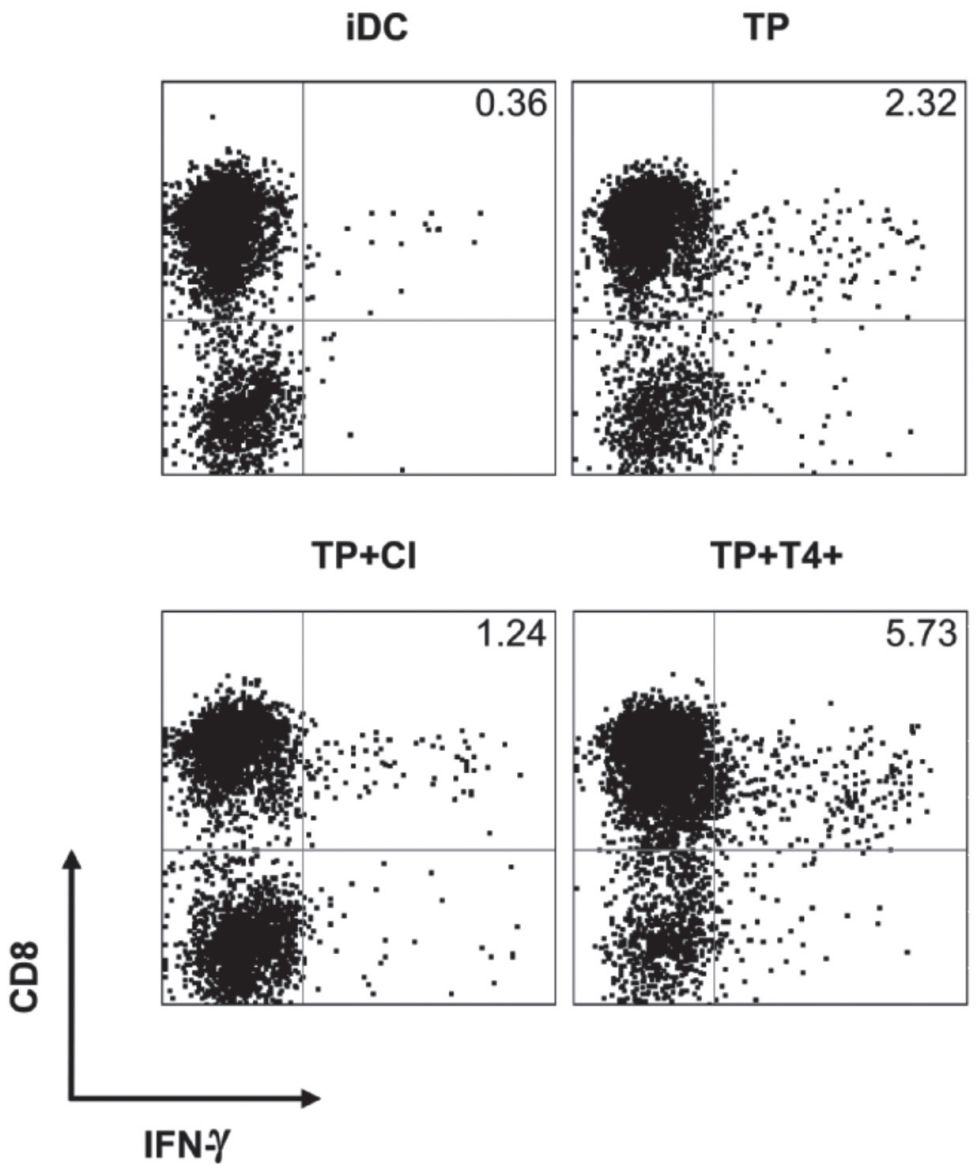

B
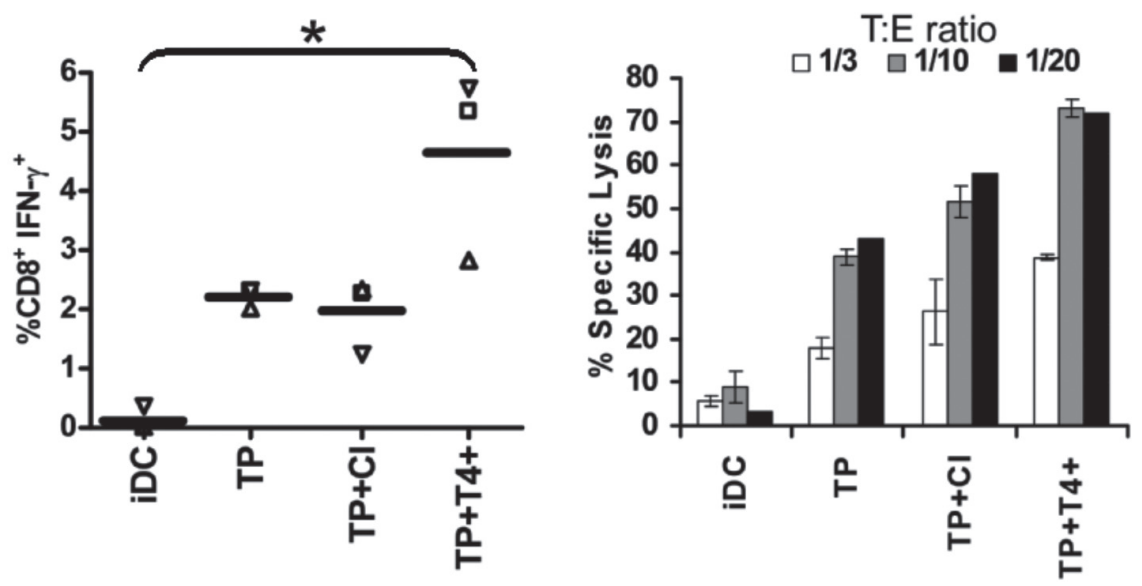

Fig. 4 DCs matured sequentially with CD4+ T cells as a secondary signal generate cytotoxic $T$ cells. DCs activated by the indicated maturation agents were loaded with Melan- $A_{(26-35)} A 27 \mathrm{~L}$ peptide, and used to stimulate autologous CD8+ T lymphocytes from healthy donors at a 1:10 DC/T cell ratio. (A) After 6 days, T cells were re-stimulated with unloaded or Melan-A peptide-loaded T2 cells for 6 hrs and the production of IFN- $\gamma$ by CD8+ T cells was measured by intracellular staining and flow cytometry. The percentages of IFN- $\gamma+$ CD8+ T cells are indicated on the dot plot. A representative experiment for one donor out of three is shown. (B) The percentage of IFN $-\gamma+$ CD8+ T cells responding to Melan-A peptide was determined from three independent experiments. Each symbol represents one donor. (C) CD8+ T cells were incubated for 4 hrs with Melan-A peptide and ${ }^{51} \mathrm{Cr}$ loaded T2 cells at Effector:Target ratios of 3:1 (white), 10:1 (grey), 20:1 (black). The percentage of lysis induced by DC-stimuladed CD8+ T cells was then measured by $\mathrm{Cr}^{51}$ release compared to spontaneous and maximal release. A representative experiment for one donor out of three is shown. 
expression of CD127 identifies memory cells (Kaech, et al., 2003). We observed that CD45RO+CD28+CD45RAint cells expressed CD127, with much higher intensity in the "TP+T4+" condition (MFI=107 compared to MFI $<65$ for all other conditions). These cells identified as CD45RO+ CD45RAint CD27+CD28+CD127hi display a phenotype typical of longlived T memory cells.

To complete the characterization of these T memory cells, we analyzed their expression of CCR7. Indeed, two mains populations of CD8+ T memory cells have been described depending on their expression of CCR7: CCR7- effector T memory cells (Tem) and CCR7+ central T memory cells (Tcm) (Sallusto, et al., 1999). We observed that the $\mathrm{T}$ memory cells obtained from stimulation with DCs sequentially matured with $\mathrm{T} 4+$ as second signals, exhibit both memory profiles,
Tem $(37.6 \%)$ and $\mathrm{Tcm}(55.7 \%)$, whereas the majority of $\mathrm{T}$ memory cells obtained from other mature DCs were mainly CCR7- Tem. Furthermore, CCR7 expression was stronger on the $\mathrm{Tcm}$ obtained from sequentially matured DCs compared to the $\mathrm{Tcm}$ obtained from other conditions (MFI=21 compare to $\mathrm{MFI}<10$ for all other conditions). Thus, our results demonstrate that sequential maturation of DCs in the presence of helper cells contributes to the generation of a long-term $T$ cell pool composed of both Tem and Tcm memory components.

\section{DISCUSSION}

Description of DCs maturation in mouse model showed that this process is a multi-step phenomenon, with a first maturation signal received in the periphery (inflammatory
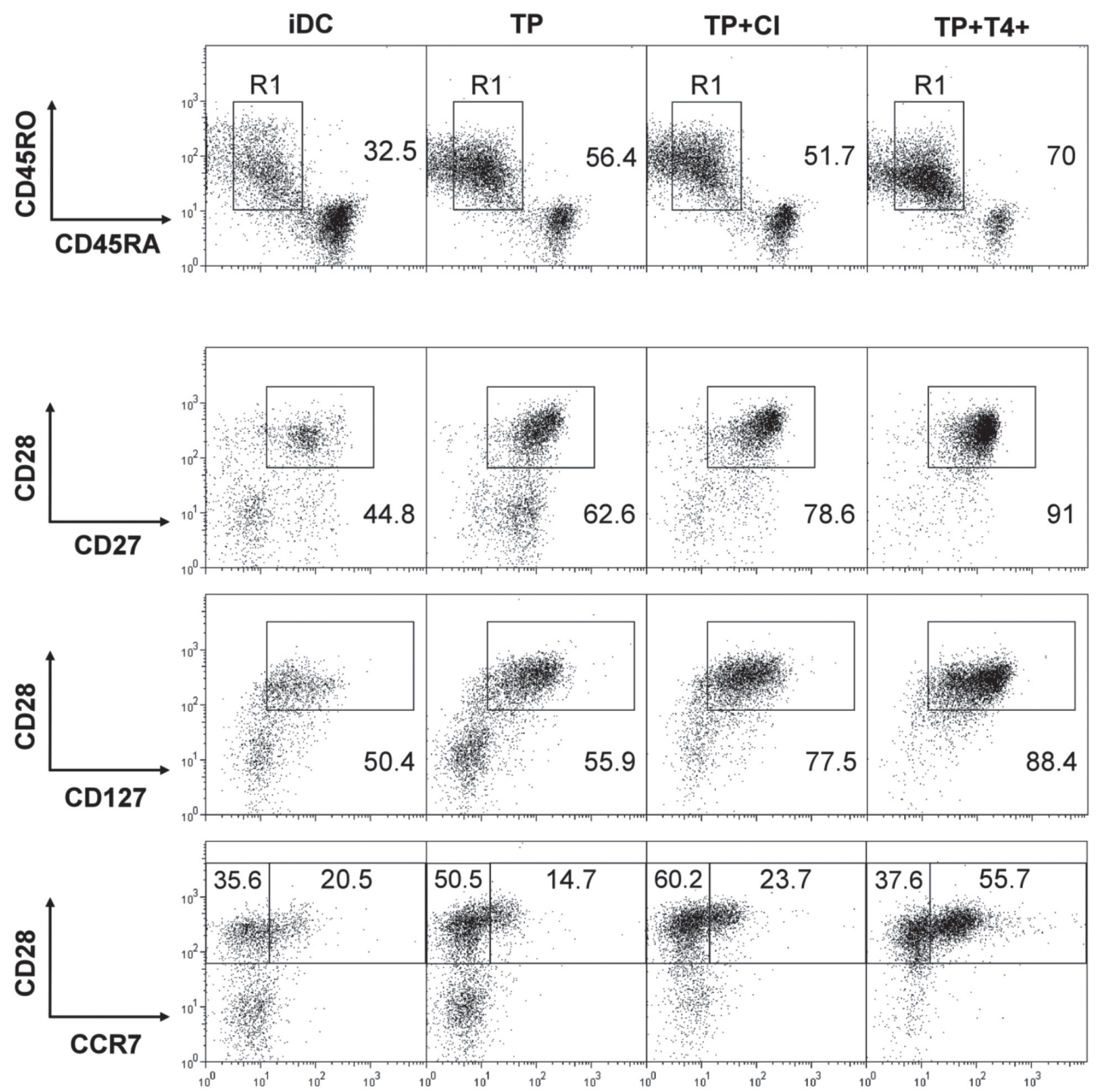

Fig. 5 DCs matured sequentially with CD4+ T cells as a secondary signal favor the generation of CD8+ T cells exhibiting a memory phenotype. DCs were activated by the indicated maturation agents, loaded with Melan- $A_{(26-35)}$ A27L peptide, and used to stimulate autologous CD8+ T lymphocytes at a $D C / T$ cell ratio of 1:10. After 15 days, the CD8+ $T$ cell memory profile was determined by immunofluorescence and flow cytometry. T cells were gated according to their morphological properties and CD28, CD27, CD127 and CCR7 expression was studied on the CD45RO+ CD45RAint T cell population (R1 gate). The percentage of gated cells is indicated on the dot plot. A representative experiment for one donor out of three is shown. 
and/or pathogenic signals), which at least induces DC activation and their migration to lymph nodes, where they receive additional maturation signals from CD4+ $\mathrm{T}$ cells (Banchereau and Steinman, 1998). In our in vitro study, we characterized, for the first time, this sequential maturation of human DCs with activated CD4+ T cells as a second signal. We used TNF- $\alpha$ and poly I:C as first maturation signals, since these two signals are relevant as inflammation and pathogenic stimuli, respectively, that DCs encounter in periphery. In a previous study we demonstrate that the combination of TNF- $\alpha$ and poly I:C is the most efficient in inducing the complete activation of human DCs compared to a large variety of maturation molecules or cytokine cocktails (Spisek, 2001; Gregoire, 2003). These two molecules are also relevant for clinical applications of this maturation process (Mc IlRoy et al., 2003; Royer et al., 2006). In this study, we show that DC maturation requires second signals delivered by activated CD4+ T cells a few hours after exposure to peripheral maturation stimuli to fully initiate CD8 $+\mathrm{T}$ cell responses. DCs activated by this sequential procedure exhibit a more profoundly mature phenotype, which improves their ability to induce differentiation of tumor antigen-specific CTL with a long-term memory phenotype.

It was previously demonstrated in murine models that in secondary lymphoid organs, activation of CD4+ T helper cells by mature DC results in stimulation and conditioning of DCs by CD4+ T cells that "license" DCs to induce CTL responses. It has been well established that CD40-L is one of the main activated $\mathrm{CD} 4+\mathrm{T}$ cell signals provided to DCs and that CD40-L/CD40 interactions initiate differentiation of naïve CD8+ T cells to effector CTL by DCs (Bennett, et al., 1998, Ridge, et al., 1998, Schoenberger, et al., 1998, Johnson, et al., 2009). In our study, we show that activated allogeneic $\mathrm{CD} 4+\mathrm{T}$ cells used as a second signal are more efficient at maturing monocyte-derived human DCs than the combination of CD40-L and IFN- $\gamma$, suggesting a more complex exchange of signals between these two types of cells. In addition to CD40-L and IFN- $\gamma$, CD4+ T cells produce other factors such as molecules of the TNF family (TNF- $\alpha$; TRANCE...) and cytokines such as IL-2, which may explain the difference observed in DC between the CD40-L/IFN- $\gamma$ combination and activated CD4+ T cells used as second signals.

Furthermore, these CD4+ T cell/DC interactions not only affect the maturation phenotype of DCs, but also induce the secretion of chemokines by DCs, such as CCL3 and CCL4 (Mip1- $\alpha$ and $-\beta$ ). Chemokines are reported in murine models to have a chemotactic effect on naïve CD8+ T cells (Castellino, et al., 2006) and to favor the encounter of rare antigen-specific naïve CD8+ precursors with mature DCs. In our study, we show that DCs exposed to activated CD4+ $\mathrm{T}$ cells secrete high quantities of these two chemokines, which in humans may have the same chemotactic effect on naïve CD8+ T cells as observed in mice. Furthermore, it has been shown that CCL3 and CCL4 produced by T helperconditioned DCs play a role in the generation of pre-memory CD8 $+\mathrm{T}$ cells characterized by a high expression of IL-6R $\alpha$ and IL-7R $\alpha$ (Castellino and Germain, 2007). Survival of these pre-memory CD8+ T cells is dependent on IL-6, even in the presence of IL-7 (used under our experimental conditions). In addition, it has been shown that IL-6 produced upon TLR signaling can block CD4+CD25+ T cell-mediated suppression (Pasare and Medzhitov, 2003). These effects of IL-6, CCL3 and CCL4 on the immune response fit well with our present observations. Indeed, activated CD4+ $\mathrm{T}$ cells exposed to mature DCs, which produced the highest amount of IL-6, CCL3 and CCL4, induced Melan-A-specific CTL, which exhibited the strongest long-term memory phenotype (CD27+ CD28+ CD45RAint CD45RO+ CD127+ CD8+) (Powell, et al., 2005).We also observed a dramatic effect of activated CD4+ T cells on cytokine production, notably IL-12, by mature DCs. IL-12 secretion by DCs skews the immune response towards a Th1 profile (Macatonia, et al., 1995, Hilkens, et al., 1997), whereas IL-10 inhibits it (O'Garra and Vieira, 2007). In our study, activated CD4+ T cell-exposed mature DCs, which produced high amounts of IL-12, were the most efficient to induce a CTL response against a tumor-associated antigen such as Melan-A from HLA-A*0201+ healthy blood donors. Therefore, the balance of effect between IL-10 and IL-12 is in favor of IL-12, skewing the immune response towards a Th1 profile.

Several anti-tumor immunotherapeutic strategies have been developed during the last decade, such as injection of anti-tumor-specific $\mathrm{T}$ cells or tumor antigen-loaded DCs, notably to treat melanoma patients. Despite induction of antitumor $\mathrm{T}$ cell responses and encouraging clinical results, one common problem encountered during these protocols is the failure to induce a long-lasting anti-tumor $\mathrm{T}$ cell response (Dudley and Rosenberg, 2007, Palucka, et al., 2007). Indeed, in adoptive immunotherapy clinical trials, anti-tumor-specific $\mathrm{T}$ cells are detected for only a few days following injection in the patients (Dudley, et al., 2001, Yee, et al., 2002). In DCbased clinical trials, progression of the disease after a period of stabilization was described when the anti-tumor-specific CTL response ceases (Andersen, et al., 2001), and a re-stimulation of anti-tumor-specific $\mathrm{T}$ cells is required for these cells to be detected several weeks after the DC injection (Palucka, et al., 2005, Simon, et al., 2009). Interestingly, Rosenberg's group designed a modified clinical trial based on immunotherapy to increase the survival of tumor-antigen-specific CTLs injected to patients (Dudley, et al., 2002). They treated the patients with a lympho-depleting chemotherapeutic regimen prior to the injection of $\mathrm{T}$ cells to limit the negative effect of CD4+CD25+ regulatory $\mathrm{T}$ cells and to disrupt homeostatic $\mathrm{T}$ cell regulation. The authors succeeded in inducing a long-lasting anti-tumorspecific CTL response that was still detectable in the blood of responding patients two months after the injection. They were also able to define the phenotype of these tumor-reactive cells as effector $\mathrm{T}$ memory cells (Tem) characterized by a CD27+CD28+CD45RAintCD62L-CCR7-CD127+ phenotype (Powell, et al., 2005). However, in a mouse model, transfer of anti-tumor central $\mathrm{T}$ memory cells $(\mathrm{T} \mathrm{cm})$ was shown to be more efficient at inducing tumor regression than transfer of anti-tumor Tem (Klebanoff, et al., 2005). This suggests that both memory subsets play a complementary role in $\mathrm{T}$ cell memory responses. In the periphery, Tem are able to quickly lyse cells harboring the antigen. This cytotoxic response is reinforced by a new pool of effector $\mathrm{T}$ cells differentiated from $\mathrm{Tcm}$ exposed to the antigen in secondary lymphoid organs. Thus, it is likely that the presence of both subsets is required for optimal $\mathrm{T}$ memory cell responses. In our study, we demonstrate that DC sequentially matured with poly I:C plus TNF- $\alpha$ followed by activated CD4+ T cells, allow the priming of tumor-associated antigen-specific CTL, which differentiate in vitro into both Tem and Tcm memory subsets. The Tem 
exhibited a CD27+CD28+CD45RAintCD127+ phenotype similar to the persistent anti-tumor T cells described by Powell et al (Powell, et al., 2005).

Altogether, the results of our study demonstrate for the first time that sequential maturation of human DCs using activated CD4+ T cells as a second signal greatly increases the capacity of DCs to prime a complete CTL response, with the establishment of a long-lasting anti-tumor T memory cell pool containing both effector and central components. This work has important implications for the development of DC-based immunotherapy and highlights the requirement of $\mathrm{T}$ helperderived signals in the DC maturation process.

\section{ACKNOWLEDGEMENTS}

The authors declare no conflict of interest.

We thank Delphine Coulais from the "Plateforme de Développement et de Transfert à la Clinique" for her technical help and for providing purified monocytes. This work was supported by grants from the INSERM, the "Association pour la Recherche contre le Cancer" and "La Région Pays de la Loire".

\section{REFERENCES}

ANDERSEN MH, KEIKAVOUSSI P, BROCKER EB, SCHULER-THURNER B, JONASSEN M, SONDERGAARD I, STRATEN PT, BECKER JC, KAMPGEN E (2001) Induction of systemic CTL responses in melanoma patients by dendritic cell vaccination: cessation of CTL responses is associated with disease progression. Int J Cancer 94:820-824.

ARENS R, SCHOENBERGER SP (2010) Plasticity in programming of effector and memory CD8 T-cell formation. Immunol Rev 235:190-205.

BANCHEREAU J, STEINMAN RM (1998) Dendritic cells and the control of immunity. Nature 392:245-252.

BENNETT SR, CARBONE FR, KARAMALIS F, MILLER JF, HEATH WR (1997) Induction of a CD8+ cytotoxic T lymphocyte response by crosspriming requires cognate CD4+ T cell help. J Exp Med 186:65-70.

BENNETT SR, CARBONE FR, KARAMALIS F, FLAVELL RA, MILLER JF, HEATH WR (1998) Help for cytotoxic-T-cell responses is mediated by CD40 signalling. Nature 393:478-480.

CASTELLINO F, GERMAIN RN (2006) Cooperation between CD4+ and CD8+ T cells: when, where, and how. Annu Rev Immunol 24:519-540.

CASTELLINO F, HUANG AY, ALTAN-BONNET G, STOLL S, SCHEINECKER C, GERMAIN RN (2006) Chemokines enhance immunity by guiding naive CD8+ $\mathrm{T}$ cells to sites of $\mathrm{CD} 4+\mathrm{T}$ celldendritic cell interaction. Nature 440:890-895.

CASTELLINO F, GERMAIN RN (2007) Chemokine-guided CD4+ T cell help enhances generation of IL-6RalphahighIL-7Ralpha high prememory CD8+ T cells. J Immunol 178:778-787.

DUDLEY ME, WUNDERLICH J, NISHIMURA MI, YU D, YANG JC, TOPALIAN SL, SCHWARTZENTRUBER DJ, HWU P, MARINCOLA FM, SHERRY R, LEITMAN SF, ROSENBERG SA (2001) Adoptive transfer of cloned melanoma-reactive T lymphocytes for the treatment of patients with metastatic melanoma. J Immunother 24:363-373.

DUDLEY ME, WUNDERLICH JR, ROBBINS PF, YANG JC, HWU P, SCHWARTZENTRUBER DJ, TOPALIAN SL, SHERRY R, RESTIFO NP, HUBICKI AM, ROBINSON MR, RAFFELD M, DURAY P, SEIPP CA, ROGERS-FREEZER L, MORTON KE, MAVROUKAKIS SA, WHITE DE, ROSENBERG SA (2002) Cancer regression and autoimmunity in patients after clonal repopulation with antitumor lymphocytes. Science 298: 850-854.

DUDLEY ME, ROSENBERG SA (2007) Adoptive cell transfer therapy. Semin Oncol 34:524-531.

GREGOIRE M, LIGEZA-POISSON C, JUGE-MORINEAU N, SPISEK R. Anti-cancer therapy using dendritic cells and apoptotic tumour cells: pre-clinical data in human mesothelioma and acute myeloid leukaemia. (2003) 21(7-8):791-4

HILKENS CM, KALINSKI P, DE BOER M, KAPSENBERG ML (1997) Human dendritic cells require exogenous interleukin-12-inducing factors to direct the development of naive T-helper cells toward the Th1 phenotype. Blood 90:1920-1926.
JOHNSON S, ZHAN Y, SUTHERLAND RM, MOUNT AM, BEDOUI S, BRADY JL, CARRINGTON EM, BROWN LE, BELZ GT, HEATH WR, LEW AM (2009) Selected Toll-like receptor ligands and viruses promote helper-independent cytotoxic $\mathrm{T}$ cell priming by upregulating $\mathrm{CD} 40 \mathrm{~L}$ on dendritic cells. Immunity 30:218-227.

KAECH SM, TAN JT, WHERRY EJ, KONIECZNY BT, SURH CD, AHMED R (2003) Selective expression of the interleukin 7 receptor identifies effector CD8 T cells that give rise to long-lived memory cells. Nat Immunol 4:1191-1198.

KLEBANOFF CA, GATTINONI L, TORABI-PARIZI P, KERSTANN K, CARDONES AR, FINKELSTEIN SE, PALMER DC, ANTONY PA, HWANG ST, ROSENBERG SA, WALDMANN TA, RESTIFO NP (2005) Central memory self/tumor-reactive CD8+ T cells confer superior antitumor immunity compared with effector $t$ memory cells. Proc Natl Acad Sci U S A 102:9571-9576.

LANGENKAMP A, MESSI M, LANZAVECCHIA A, SALLUSTO F (2000) Kinetics of dendritic cell activation: impact on priming of TH1, TH2 and nonpolarized T cells. Nat Immunol 1:311-316.

LU Z, YUAN L, ZHOU X, SOTOMAYOR E, LEVITSKY HI, PARDOLL DM (2000) CD40-independent pathways of T cell help for priming of CD8(+) cytotoxic T lymphocytes. J Exp Med 191:541-550.

MACATONIA SE, HOSKEN NA, LITTON M, VIEIRA P, HSIEH CS, CULPEPPER JA, WYSOCKA M, TRINCHIERI G, MURPHY KM, O'GARRA A (1995) Dendritic cells produce IL-12 and direct the development of Th1 cells from naive CD4+ T cells. J Immunol 154: 5071-5079.

MACKEY MF, GUNN JR, MALISZEWSKY C, KIKUTANI H, NOELLE RJ, BARTH RJ, JR. (1998) Dendritic cells require maturation via CD40 to generate protective antitumor immunity. J Immunol 161:2094-2098.

MCILROY D, GREGOIRE M. (2003) Optimizing dendritic cell-based anticancer immunotherapy: maturation state does have clinical impact. Cancer Immunol Immunother 52(10):583-91.

MILLER JD, VAN DER MOST RG, AKONDY RS, GLIDEWELL JT, ALBOTT S, MASOPUST D, MURALI-KRISHNA K, MAHAR PL, EDUPUGANTI S, LALOR S, GERMON S, DEL RIO C, MULLIGAN MJ, STAPRANS SI ALTMAN JD, FEINBERG MB, AHMED R (2008) Human effector and memory CD8+ T cell responses to smallpox and yellow fever vaccines. Immunity 28:710-722.

O'GARRA A, VIEIRA P (2007) T(H)1 cells control themselves by producing interleukin-10. Nat Rev Immunol 7:425-428.

OBAR JJ, LEFRANCOIS L (2010) Memory CD8+ T cell differentiation. Ann N Y Acad Sci 1183:251-266.

PALUCKA AK, DHODAPKAR MV, PACZESNY S, UENO H, FAY J, BANCHEREAU J (2005) Boosting vaccinations with peptide-pulsed CD34+ progenitor-derived dendritic cells can expand long-lived melanoma peptide-specific CD8+ T cells in patients with metastatic melanoma. J Immunother 28:158-168.

PALUCKA AK, UENO H, FAY JW, BANCHEREAU J (2007) Taming cancer by inducing immunity via dendritic cells. Immunol Rev 220:129-150.

PASARE C, MEDZHITOV R (2003) Toll pathway-dependent blockade of $\mathrm{CD} 4+\mathrm{CD} 25+\mathrm{T}$ cell-mediated suppression by dendritic cells. Science 299:1033-1036.

POWELL DJ, JR., DUDLEY ME, ROBBINS PF, ROSENBERG SA (2005) Transition of late-stage effector T cells to CD27+ CD28+ tumor-reactive effector $\mathrm{t}$ memory cells in humans after adoptive cell transfer therapy. Blood 105:241-250.

RIDGE JP, DI ROSA F, MATZINGER P (1998) A conditioned dendritic cell can be a temporal bridge between a CD4+ T-helper and a T-killer cell. Nature 393:474-478.

ROYERr PJ, TANGUY-ROYER S, EBSTEIN F, SAPEDE C, SIMON T, BARBIEUX I, OGER R, GREGOIRE M. (2006) Culture medium and protein supplementation in the generation and maturation of dendritic cells. Scand J Immunol. 63(6):401-9.

SALLUSTO F, LENIG D, FORSTER R, LIPP M, LANZAVECCHIA A (1999) Two subsets of memory $\mathrm{T}$ lymphocytes with distinct homing potentials and effector functions. Nature 401:708-712.

SALTER RD, CRESSWELL P (1986) Impaired assembly and transport of HLA-A and -B antigens in a mutant TxB cell hybrid. EMBO J 5:943-949.

SCHOENBERGER SP, TOES RE, VAN DER VOORT EI, OFFRINGA R, MELIEF CJ (1998) T-cell help for cytotoxic T lymphocytes is mediated by CD40-CD40L interactions. Nature 393:480-483.

SCHRODER K, HERTZOG PJ, RAVASI T, HUME DA (2004) Interferongamma: an overview of signals, mechanisms and functions. J Leukoc Biol 75:163-189. 
SIMON T, FONTENEAU JF, GREGOIRE M (2009) Dendritic cell preparation for immunotherapeutic interventions. Immunotherapy 1:289-302.

SPISEK R, BRETAUDEAU L, BARBIEUX I, MEFLAH K, GREGOIRE M. (2001) Standardized generation of fully mature p70 IL-12 secreting monocyte-derived dendritic cells for clinical use. Cancer Immunol Immunother $8: 417-27$.

SPISEK R, BOUGRAS G, EBSTEIN F, MASSE D, MEFLAH K, MCILROY D, GREGOIRE M (2003) Transient exposure of dendritic cells to maturation stimuli is sufficient to induce complete phenotypic maturation while preserving their capacity to respond to subsequent restimulation. Cancer Immunol Immunother 52:445-454.

YEE C, THOMPSON JA, BYRD D, RIDDELL SR, ROCHE P, CELIS E, GREENBERG PD (2002) Adoptive T cell therapy using antigen-specific $\mathrm{CD} 8+\mathrm{T}$ cell clones for the treatment of patients with metastatic melanoma: in vivo persistence, migration, and antitumor effect of transferred T cells. Proc Natl Acad Sci U S A 99:16168-16173. 
5 Simon.indd 44

$29-03-12 \quad 13: 04$ 